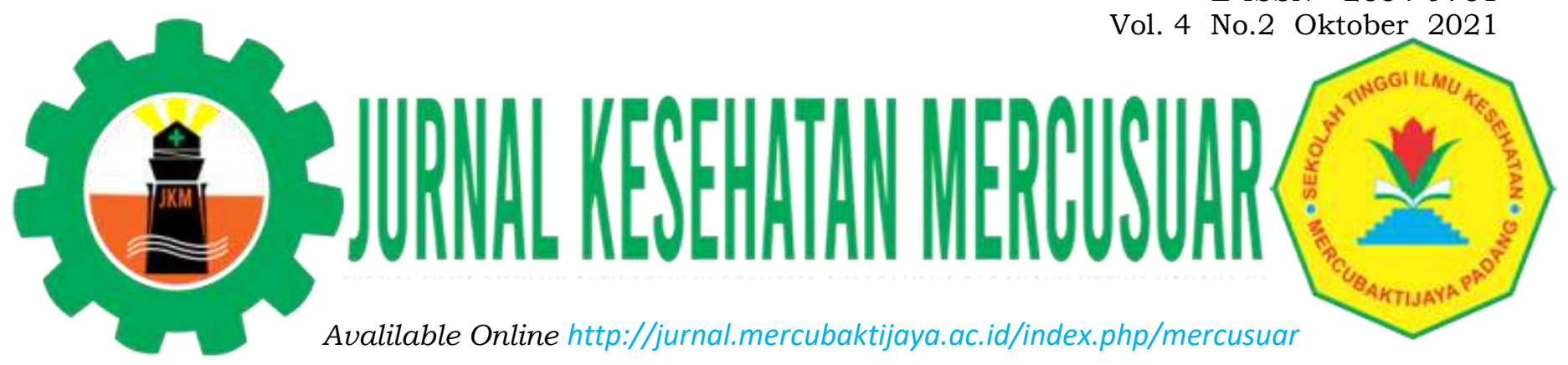

\title{
ANALISIS FAKTOR YANG BERHUBUNGAN DENGAN KEPATUHAN PEKERJA MENGGUNAKAN ALAT PELINDUNG DIRI
}

\author{
Ratna Lestari $^{1^{*}}$, Agus Warseno ${ }^{2}$ \\ ${ }^{1,2}$ Program Studi Keperawatan, Fakultas Kesehatan, Universitas Jenderal Achmad Yani \\ Yogyakarta, Jalan Brawijaya, Sleman, DIY, Indonesia \\ *Email korespondensi: ratnalestarigg@gmail.com
}

\begin{abstract}
The implementation of occupational health and safety among the industrial circle and society in Indonesia is still relatively low, thus resulted in an occupational accident. Preventive attempts or anticipation for occupational accidents can be conducted by fostering habituation of order, discipline, and maintaining a healthy and safe environment through worker compliance to Personal Protective Equipment (PPE). The use of Personal Protective Equipment will safeguard the workers from potential hazards in the workplace. This research aims to find factors related to worker compliance in using Personal Protective Equipment in Madubaru Inc. Yogyakarta. This research is correlation research with the cross-sectional approach. The sample in this research are 86 workers, in steam boiler station and milling obtained using purposive sampling. Data collection is conducted through the Personal Protective Equipment compliance questionnaire. Additionally, data analysis is performed using a correlation analysis test with chi-square with a confidence level of $95 \%(\alpha=0.05)$. The finding of this research showed that $76.7 \%$ of workers did not comply with the utilization of PPE. All variables were not related to the worker compliance in using PPE that is age (p-value 0. 942), education (p-value 0. 300), the length of employment (p-value 0. 077), employment status ( $p$-value 0.797), knowledge ( $p$-value 0.961), attitude ( $p$-value 0.780), motivation ( $p$ value 0. 487), supervision ( $p$-value 0.674), and PPE availability ( $p$-value 0.222It can be concluded that individual characteristics, knowledge, attitude, motivation, supervision, and availibility had no correlation with PPE compliance in Madubaru Inc. Yogyakarta.
\end{abstract}

Keywords: Compliance; Personal Protective Equipment; Workers

\begin{abstract}
ABSTRAK
Penerapan kesehatan dan keselamatan kerja (K3) di Indonesia masih tergolong rendah pada kalangan industri dan masyarakat, hal ini menyebabkan terjadinya kecelakaan kerja. Upaya pencegahan atau mengantisipasi kecelakaan kerja dapat dilakukan dengan membiasakan ketertiban, kedisiplinan, dan menjaga lingkungan yang sehat dan aman melalui kepatuhan pekerja menggunakan Alat Pelindung Diri (APD). Penggunaan APD akan melindungi pekerja dari potensi bahaya di tempat kerja. Penelitian ini bertujuan untuk mengetahui faktor-faktor yang berhubungan dengan kepatuhan pekerja dalam menggunakan APD di PT Madubaru Yogyakarta. Penelitian ini merupakan penelitian korelasi dengan pendekatan cross sectional. Sampel dalam penelitian ini adalah pekerja di unit Stasiun Ketel Uap dan Penggilingan sejumlah 86 orang dengan menggunakan purposive sampling. Pengumpulan data menggunakan kuesioner kepatuhan APD, dan analisis data dengan uji korelasi chi square dengan tingkat kepercayaan $95 \%(\alpha=0,05)$. Hasil penelitian menunjukkan bahwa $76,7 \%$ pekerja tidak patuh dalam menggunakan APD. Semua variabel tidak berhubungan dengan kepatuhan pekerja dalam menggunakan Alat Pelindung Diri yaitu usia ( $p$-value 0,942), pendidikan ( $p$-value 0,300), lama kerja ( $p$-value 0,077),
\end{abstract}


Ratna Lestari, Agus Warseno| Analisis Faktor yang Berhubungan dengan Kepatuhan Pekerja Menggunakan Alat Pelindung Diri

status kepegawaian ( $p$-value 0,797$)$, pengetahuan ( $p$-value 0,961$)$, sikap ( $p$-value 0,780$)$, motivasi ( $p$-value $0,487)$, pengawasan ( $p$-value 0,674) dan ketersediaan APD ( $p$-value 0,222). Dapat disimpulkan bahwa tidak ada hubungan antara karakteristik pekerja, pengetahuan, sikap, motivasi, pengawasan, dan ketersediaan deng.an kepatuhan menggunakan alat pelindung diri pada pekerja di PT Madubaru Yogyakarta

Kata Kunci : alat pelindung diri; kepatuhan; pekerja

\section{PENDAHULUAN}

Gula menjadi salah satu komoditas perdagangan utama, karena termasuk kebutuhan pokok masyarakat. Dalam rangka pemenuhan bahan pokok tersebut, PT Madubaru sebagai perusahaan agro industri terus berupaya meningkatkan produksi gula untuk memenuhi kebutuhan tersebut. Oleh karena itu sejalan dengan peningkatan produksi maka dibutuhkan tenaga kerja yang produktif.

Produktivitas pekerja dapat dinilai dari hasil kerja / output dengan waktu yang dibutuhkan. Untuk mencapai target, terkadang pekerja mengabaikan keselamatan dirinya di tempat kerja. Berdasarkan hasil laporan tahunan klinik PT Madubaru, terjadi 26,72\% kecelakaan kerja sejak tahun 20192020 dari 116 pekerja yang mengalami kecelakaan kerja. Kecelakaan kerja yang sering terjadi pada karyawan khususnya di stasiun penggilingan dan penguapan seperti jatuh dari ketinggian lantai penggilingan, terjepitnya tangan di penutup mesin, luka bakar karena api dari ketel uap, kepala terbentur pintu ketel, dan heat stress karena suhu di stasiun ketel mencapai $1300^{\circ} \mathrm{C}$.

Kondisi penerapan kesehatan dan keselamatan kerja (K3) di Indonesia masih tergolong rendah pada kalangan industri dan masyarakat, hal ini menyebabkan terjadinya kecelakaan kerja. Kesehatan dan keselamatan kerja (K3) merupakan cara untuk menciptakan suasana kerja yang sehat, aman dan nyaman sehingga dapat memberikan dampak positif dengan meningkatkan produktivitas pekerja dan menghindari pekerja dari kecelakaan kerja (Ibrahim,
2017). K3 memberikan perlindungan kepada tenaga kerja merujuk pada keadaan fisik dan psikologis pekerja selama berada di kawasan tempat kerja (Suma'mur, 2014).

Kecelakaan kerja yang terjadi pada karyawan, salah satunya dipengaruhi oleh ketidakpatuhan terhadap prosedur dan penggunaan APD yang ditetapkan perusahaan. Berdasarkan penelitian sebelumnya dilaporkan sebanyak 70,4\% pekerja yang tidak memakai APD sesuai syarat di perusahaan pembuat triplek PT PSUT Jambi mengalami dermatitis alergi dengan nilai p 0,014 (Margareta Pratiwi \& \& Eka, 2016). Pekerja yang tidak patuh memakai APD berpotensi 4,7 kali lebih besar mengalami dermatitis alergi. Didukung penelitian lainnya bahwa kecelakaan kerja juga terjadi pada pekerja di PT PLN Bangkinang Kota akibat pemakaian APD yang tidak lengkap sebesar 66,7\% dengan nilai p 0,000 (Puteri \& Afrianti, 2019). Sejalan dengan dua penelitian sebelumnya, penelitian Wahyuni melaporkan risiko kecelakaan kerja seperti tertusuk, tersayat, terpotong semakin tinggi pada pekerja yang tidak patuh memakai APD di Industri Garmen Semarang sebesar 82,1\% dengan nilai p 0,00 (Alfidyani et al., 2020).

Upaya pencegahan atau mengantisipasi kecelakaan kerja dapat dilakukan dengan membiasakan ketertiban, kedisiplinan, dan menjaga lingkungan yang sehat, aman serta nyaman (Indrayani \& Sulianti, 2014). APD sebagai salah satu hirarki pengendalian bahaya di tempat kerja memiliki peran penting menjaga keselamatan dan keamanan bagi pekerja. Pekerja harus menggunakan 
Ratna Lestari, Agus Warseno| Analisis Faktor yang Berhubungan dengan Kepatuhan Pekerja Menggunakan Alat Pelindung Diri

APD yang sesuai saat memasuki tempat kerja (Andriyanto, 2017). Karyawan di PT Madubaru terutama di stasiun ketel dan penggilingan minimal wajib menggunakan APD berupa sepatu boots, safety helmet, masker kain, dan sarung tangan kulit. Hasil observasi peneliti pada studi pendahuluan memperoleh data bahwa sebanyak 3 karyawan tidak menggunakan safety helmet, 2 orang lainnya tidak menggunakan safety shoes dan mayoritas tidak menggunakan masker dan sarung tangan kulit.

Berdasarkan latar belakang di atas penting untuk dilakukan penelitian lebih lanjut tentang faktor-faktor yang berhubungan dengan kepatuhan pekerja pada penggunaan APD di PT Madubaru, Bantul.

\section{METODE PENELITIAN}

Penelitian ini merupakan penelitian korelasi dengan pendekatan cross sectional. Penelitian dilakukan di PT Madubaru Wilayah Bantul Yogyakarta. Penelitian dilakukan dari bulan Agustus sampai Oktober 2020. Teknik pengambilan sampel dalam penelitian ini menggunakan purposive sampling, dengan jumlah sampel sebanyak 86 pekerja di stasiun penggilingan dan ketel uap. Kriteria inklusi dan eksklusi penelitian ini yaitu para pekerja yang ada di Pabrik Madubaru, usia minimal 18 tahun, dan lama kerja minimal 6 bulan. Sedangkan kriteria eksklusinya adalah pekerja yang tidak hadir dan tidak bersedia terlibat dalam penelitian. Variabel bebas dalam penelitian ini adalah pengetahuan, sikap, motivasi, pengawasan, dan ketersediaan APD. Varibel terikat dalam penelitian ini adalah kepatuhan pekerja menggunakan APD. Pengumpulan data menggunakan kuesioner dan lembar observasi kepatuhan penggunaan APD yang dibuat sendiri oleh peneliti mengacu pada buku Occupational Health Nursing (Oakley, 2008). Kuesioner dan lembar observasi ini sudah melalui tahap uji expert dengan content validity index dari 3 orang pakar yaitu 2 orang dosen keperawatan pada bidang kesehatan kerja dan telah mengikuti pelatihan kesehatan kerja serta 1 orang praktisi pembina kesehatan dan keselamatan kerja (K3) dengan nilai I-CVI adalah 1. Analisis data menggunakan uji korelasi chi square dengan tingkat kepercayaan 95\% ( $\alpha=$ 0,05). Penelitian ini telah dinyatakan lolos uji etik dari Universitas Jenderal Achmad Yani Yogyakarta dengan No Skep/024/KEPK/III/2020.

\section{HASIL DAN PEMBAHASAN \\ Analisis Univariat}

Hasil penelitian ini didapatkan berdasarkan variabel bebas yaitu faktorfaktor yang berhubungan dengan kepatuhan pekerja menggunakan APD dan gambaran penggunaan APD yang digambarkan pada tabel di bawah ini.

\section{Tabel 1. Distribusi frekuensi faktor-faktor yang berhubungan dengan kepatuhan menggunakan APD di PT Madubaru Oktober 2020 (n=86)}

\begin{tabular}{llcc}
\hline No & Variabel & Frekuensi (n) & Persentase (\%) \\
\hline 1 & Pengetahuan & & \\
& Baik & 52 & 60,5 \\
& Kurang baik & 34 & 39,5 \\
\hline \multicolumn{2}{l}{ Total } & $\mathbf{8 6}$ & $\mathbf{1 0 0}$ \\
\hline 2 & Sikap & & \\
& Baik & 58 & 67,4 \\
\hline
\end{tabular}


Ratna Lestari, Agus Warseno| Analisis Faktor yang Berhubungan dengan Kepatuhan Pekerja Menggunakan Alat Pelindung Diri

\begin{tabular}{llcc}
\hline No & Variabel & Frekuensi (n) & Persenta \\
\hline & Kurang baik & 28 & 32,6 \\
\hline \multirow{3}{*}{3} & Total & $\mathbf{8 6}$ & $\mathbf{1 0 0}$ \\
& Motivasi & & \\
& Positif & 53 & 61,6 \\
& Negatif & 33 & 38,4 \\
\hline \multirow{4}{*}{ Total } & Pengawasan & $\mathbf{8 6}$ & $\mathbf{1 0 0}$ \\
\hline & Baik & 53 & 61,6 \\
& Kurang baik & 33 & 38,4 \\
\hline \multirow{4}{*}{ Total } & $\mathbf{8 6}$ & $\mathbf{1 0 0}$ \\
& & & \\
\hline 5 & Ketersediaan & & 64 \\
& Memadai & 55 & 36 \\
\hline & Tidak memadai & 31 & $\mathbf{1 0 0}$ \\
\hline \multirow{4}{*}{ Total } & $\mathbf{8 6}$ &
\end{tabular}

Sumber: Data Primer, 2020

* pengetahuan diukur berdasarkan mean, dikatakan baik apabila mean $\geq 10,5$

*sikap diukur berdasarkan mean, dikatakan baik apabila mean $\geq 6,9$

*motivasi diukur berdasarkan mean, dikatakan positif apabila mean $\geq 9,1$

*pengawasan diukur berdasarkan mean, dikatakan baik apabila mean $\geq 15,6$

*ketersediaan APD berdasarkan mean, dikatakan memadai apabila mean $\geq 3,3$

Berdasarkan tabel 1 dapat diketahui bahwa mayoritas pengetahuan pekerja tentang APD dalam kategori baik yaitu 60,5\%. Sikap pekerja terhadap APD juga menunjukkan kategori baik sebesar $67,4 \%$, pekerja juga memiliki motivasi yang positif dalam menggunakan APD sebesar 61,6\%. Pekerja juga menyampaikan pengawasan dalam penggunaan APD dalam kategori baik sebesar $61,6 \%$, serta ketersediaan APD yang memadai sebesar $64 \%$.

Tabel 2. Distribusi Frekuensi Kepatuhan Pekerja Menggunakan APD di PT Madubaru Oktober $2020(n=86)$

\begin{tabular}{lcc}
\hline Kepatuhan & Frekuensi (n) & Persentase (\%) \\
\hline Patuh & 20 & 23,3 \\
Tidak Patuh & 66 & 76,7 \\
\hline Total & $\mathbf{8 6}$ & $\mathbf{1 0 0}$ \\
\hline
\end{tabular}

Sumber : data primer, 2020

*dikatakan patuh apabila pekerja menggunakan semua APD minimal di PT Madubaru diantaranya sepatu boots, safety helmet, masker kain, dan sarung tangan kulit

Tabel 2 dapat diketahui bahwa mayoritas pekerja tidak patuh dalam menggunakan APD di tempat kerja sebesar
76,7\%. Berdasarkan UU No 1 tahun 1970 pasal 12 tentang keselamatan kerja dijelaskan bahwa setiap pekerja wajib memakai alat 
Ratna Lestari, Agus Warseno| Analisis Faktor yang Berhubungan dengan Kepatuhan Pekerja Menggunakan Alat Pelindung Diri

pelindung diri, dimana pengawasannya dilakukan oleh pengurus dalam hal ini tim Panitia Pembina Keselamatan dan Kesehatan Kerja (P2K3). Walaupun perusahaan sudah menyediakan APD bagi pekerja, namun masih ada pekerja yang tidak mematuhi aturan penggunaan APD dikarenakan fungsi APD sudah tidak sesuai seperti safety helm dan sepatu boots, sehingga tidak digunakan oleh pekerja. Akantetapi ada karyawan yang tidak mengganti APDnya walaupun tidak berfungsi optimal dengan alasan malas dan tidak ada pengaruhnya baik memakai APD atau tidak. Berdasarkan hasil yang didapatkan, pekerja menyatakan APD memadai, hal ini dilihat berdasarkan jumlah APD yang ada di perusahaan, namun belum menilai berfungsi atau tidak. Dalam UU No
1 tahun 1970 pasal 9 dan 12, dinyatakan bahwa ketersediaan APD minimal sesuai jumlah pekerja, jenis pekerjaan, dan berfungsi dengan baik.

Sejalan dengan teori Green bahwa dalam menciptakan perilaku kesehatan perlu didukung oleh enabling factor (faktor pemudah) salah satunya adalah ketersediaan sarana dan prasarana. Selain itu masih ada pekerja tidak mematuhi aturan dalam penggunaan APD karena faktor internal seperti keleluasaan bekerjanya terganggu jika menggunakan APD. Hasil penelitian ini sesuai dengan penelitian (Mehrparvar et al., 2012) bahwa beberapa alasan pekerja tidak menggunakan APD diantaranya merasa tidak nyaman, kesulitan dalam memakai APD, dan mengganggu komunikasi.

\section{Analisis Bivariat}

Tabel 3. Tabulasi Silang dan Hasil Uji Chi Square Faktor-faktor yang Berhubungan dengan Kepatuhan Pekerja Menggunakan APD di PT Madubaru, Oktober 2020 (n=86)

\begin{tabular}{|c|c|c|c|c|c|c|c|}
\hline \multirow{3}{*}{ Variabel } & \multicolumn{6}{|c|}{ Kepatuhan Penggunaan APD } & \multirow{3}{*}{$\begin{array}{c}P \\
\text { Value }\end{array}$} \\
\hline & \multicolumn{2}{|c|}{ Tidak Patuh } & \multicolumn{2}{|c|}{ Patuh } & \multicolumn{2}{|c|}{ Total } & \\
\hline & $\mathbf{n}$ & $\%$ & n & $\%$ & n & $\%$ & \\
\hline Pengetahuan & & & & & & & 0.961 \\
\hline Kurang Baik & 26 & $30.2 \%$ & 8 & $9.3 \%$ & 34 & $39.5 \%$ & \\
\hline Baik & 40 & $46.5 \%$ & 12 & $14.0 \%$ & 52 & $60.5 \%$ & \\
\hline Sikap & & & & & & & 0.780 \\
\hline Kurang Baik & 22 & $25.6 \%$ & 6 & $7.0 \%$ & 28 & $32.6 \%$ & \\
\hline Baik & 44 & $51.2 \%$ & 14 & $16.3 \%$ & 58 & $67.4 \%$ & \\
\hline Motivasi APD & & & & & & & 0.487 \\
\hline Negatif & 24 & $27.9 \%$ & 9 & $10.5 \%$ & 33 & $38.4 \%$ & \\
\hline Positif & 42 & $48.8 \%$ & 11 & $12.8 \%$ & 53 & $61.6 \%$ & \\
\hline Ketersediaan APD & & & & & & & 0.674 \\
\hline Kurang Memadai & 23 & $26.7 \%$ & 8 & $9.3 \%$ & 31 & $36.0 \%$ & \\
\hline Memadai & 43 & $50.0 \%$ & 12 & $14.0 \%$ & 55 & $64.0 \%$ & \\
\hline Pengawasan APD & & & & & & & 0.222 \\
\hline Kurang Baik & 23 & $26.7 \%$ & 10 & $11.6 \%$ & 33 & $38.4 \%$ & \\
\hline Baik & 43 & $50.0 \%$ & 10 & $11.6 \%$ & 53 & $61.6 \%$ & \\
\hline
\end{tabular}


Ratna Lestari, Agus Warseno| Analisis Faktor yang Berhubungan dengan Kepatuhan Pekerja Menggunakan Alat Pelindung Diri

Hasil uji statistik menggunakan chi quare menunjukkan bahwa pengetahuan APD, sikap, motivasi, ketersediaan APD, dan pengawasan APD tidak berhubungan dengan kepatuhan penggunaan APD. Temuan ini tidak sesuai dengan hasil penelitian dari (Alemu et al., 2020) yang menganalisis bahwa pengetahuan berhubungan dengan kepatuhan penggunaan APD. Sedangkan hasil penelitian lain menyatakan pengetahuan tidak berhubungan dengan kepatuhan menggunakan APD dengan nilai $\mathrm{p} 0,866$ (Putra, 2017)

Pada penelitian lain disebutkan bahwa ketersediaan APD menjadi salah satu prediktor kepatuhan dari penggunaan APD. Hasil dari hubungan pengawasan APD dengan kepatuhan penggunaan APD dalam penelitian ini tidak bermakna. Hal ini bertolak belakang dengan fungsi pengawasan penggunaan yang mampu meningkatkan kepatuhan pekerja (Annisa et al., 2020). Sedangkan dari aspek motivasi, tidak ada hubungan antara motivasi dengan penggunaan APD, sejalan dengan penelitian Rachmadiyawati dengan nilai p 0,299 (Rachmadiyawati, 2020). Pada penelitian ini, motivasi pekerja dapat dilihat dari pendapat tentang hal yang mendorong dalam menggunakan APD di PT Madubaru diantaranya adanya penghargaan, pujian, hukuman. Berdasarkan hasil penelitian didapatkan bahwa pekerja dengan motivasi yang positif masih banyak yang tidak patuh dalam menggunakan APD. Beberapa pekerja menjawab jika menggunakan APD karena takut diberikan sangsi dan apabila diawasi saja oleh atasan bukan karena merasa untuk melindungi diri dari potensi kecelakaan di tempat kerja.

Meskipun pengetahuan dan sikap tentang keselamatan kerja baik pada pekerja namun ada banyak faktor luar yang memengaruhi untuk meminimalkan kecelakaan kerja (Fatimah et al., 2019).
Tenaga kerja yang berpengetahuan baik maupun kurang baik memiliki persentase yang hampir sama untuk tidak patuh dalam menggunakan APD. Mayoritas pekerja memiliki pengetahuan yang baik namun faktanya pengetahuan baik tidak menjamin seseorang untuk patuh dalam menggunakan APD. Hal ini berkaitan dengan pengetahuan yang dimiliki pekerja berada pada tingkatan pertama yaitu mengetahui belum sampai pada tingkat memahami dan mengaplikasikan (Notoatmodjo, 2012). Selain itu secara teori, perilaku pencegahan individu terbentuk oleh interaksi kompleks yang melibatkan sosiodemografi, perilaku, dan lingkungan. Paparan informasi menjadi salah satu hal yang menentukan perilaku seseorang menjadi sehat atau tidak (Odu Ndep et al., 2020)

Dalam penelitian ini, paparan informasi yang disampaikan berupa penyuluhan tentang penggunaan APD dimana sebesar $81,4 \%$ responden menyatakan pernah mendapatkan penyuluhan APD. Walaupun sudah pernah terpapar dengan informasi dari luar tentang penggunaan APD melalui training tiap tahun, namun belum ada sangsi tegas untuk pelanggar APD. Regulasi menjadi bagian yang berperan penting dalam memastikan pekerja bekerja secara aman. Regulasi yang mengatur tentang kepatuhan penggunaan APD yang baik dan benar akan meningkatkan sekitar 3 kali lipat perilaku lebih patuh pada pekerja (Dyanita, 2018). Untuk memastikan pekerja mengaplikasikan kebijakan tersebut, dapat menggunakan sistem punishment bagi yang melanggar dan reward bagi yang mampu menjalankan dengan baik. Regulasi tentang kepatuhan penggunaan APD akan memberikan kekuatan bagi perusahaan untuk menjaga keselamatan kerja di perusahaan (Akhter et al., 2019). 
Ratna Lestari, Agus Warseno| Analisis Faktor yang Berhubungan dengan Kepatuhan Pekerja Menggunakan Alat Pelindung Diri

Disampaikan oleh Kasie Panitia Pembina Keselamatan dan Kesehatan Kerja (P2K3) bahwa belum adanya respon dari manajemen perusahaan dan pihak serikat pekerja tidak menginginkan adanya sangsi dalam perjanjian kerja bersama (PKB) bagi pekerjanya yang melanggar aturan Keselamatan dan Kesehatan Kerja (K3). Selain sangsi, penyuluhan kesehatan sebaiknya dilakukan secara rutin karena dapat meningkatkan praktik penggunaan APD pada pekerja perusahaan (Megahed, et al, 2017). Penggunaan alat APD yang baik akan menurunkan risiko kecelakaan kerja dan memaksimalkan kesehatan para pekerja (Debela et al., 2019).

\section{SIMPULAN}

Sebagian besar pekerja 60,5\% memiliki pengetahuan yang baik tentang APD, bersikap baik memiliki motivasi yang positif, pengawasan yang baik dan ketersediaan APD yang memadai Pekerja kurang patuh dalam menggunakan APD sebesar 76,7\%. Dari penelitian ini dapat disimpulkan bahwa tidak ada hubungan yang signifikan antara pengetahuan, sikap, motivasi, pengawasan, dan ketersediaan dengan kepatuhan pekerja dalam menggunakan Alat Pelindung Diri.

\section{UCAPAN TERIMAKASIH}

Pada kesempatan ini, peneliti ingin mengucapkan terima kasih kepada berbagai pihak yang telah membantu terwujudnya penelitian ini :

1. Kemenristek Dikti yang telah memberikan kesempatan untuk meneliti

2. Rektor dan Ketua LPPM Universitas Jenderal Achmad Yani Yogyakarta yang telah memotivasi dan memfasilitasi penelitian ini.

3. Reviewer atas masukan dan saran bagi perbaikan penelitian ini. Penelitian ini membutuhkan kritik dan saran yang membangun agar menjadi lebih sempurna, oleh karena itu kami akan dengan senang hati menerima segala bentuk saran dan masukan.

\section{DAFTAR PUSTAKA}

Akhter, S., Rutherford, S., \& Chu, C. (2019). Exploring the system capacity to meet occupational health and safety needs: The case of the ready-made garment industry in Bangladesh. BMC Health Services Research, 19(1), 1-7. https://doi.org/10.1186/s12913-0194291-y

Alemu, A. A., Yitayew, M., Azazeh, A., \& Kebede, S. (2020). Utilization of personal protective equipment and associated factors among building construction workers in Addis Ababa, Ethiopia, 2019. BMC Public Health, 20(1), 1-9. https://doi.org/10.1186/s12889-02008889-X

Alfidyani, K. S., Lestantyo, D., \& Wahyuni, I. (2020). Hubungan Pelatihan K3, Penggunaan APD, Pemasangan Safety Sign, dan Penerapan SOP dengan Terjadinya Risiko Kecelakaan Kerja (Studi Pada Industri Garmen Kota Semarang). Jurnal Kesehatan Masyarakat E-Journal, 8(4), 478-484.

Andriyanto, M. R. (2017). Hubungan Predisposing Factor Dengan Perilaku Penggunaan Apd. The Indonesian Journal of Occupational Safety and Health, 6(1), 37. https://doi.org/10.20473/ijosh.v6i1.2017 $.37-47$

Annisa, R., Manullang, H. F., \& Simanjuntak, Y. O. (2020). Determinan Kepatuhan Penggunaan Alat Pelindung Diri (APD) Pada Pekerja PT. X Proyek Pembangunan Tahun 2019. Jurnal Penelitian Kesmasy, 2(2), 25-39. 
Ratna Lestari, Agus Warseno| Analisis Faktor yang Berhubungan dengan Kepatuhan Pekerja Menggunakan Alat Pelindung Diri

https://doi.org/10.36656/jpksy.v2i2.248

Debela, M. B., Taferi, G. R., \& Assefa, M. (2019). Occupational Exposure to Hand-arm Vibration and Associated Factors among Metehara Sugar Industry Workers : East-shoa , Ethiopia Journal of Environmental Hazards. Journal of Environmental Hazards, 2(1), 1-8.

Dyanita, F. (2018). Kepatuhan Terhadap Sop Ketinggian Pada Pekerja Konstruksi. The Indonesian Journal of Occupational Safety and Health, 6(2), 225.

https://doi.org/10.20473/ijosh.v6i2.2017 .225-234

Fatimah, N. A., Nurwijayanti, N., \& Farida, S. (2019). Analysis of Knowledge, Attitude, Employee Action in the Use of Personal Protective Equipment (PPE) with Work Accidents. Journal for Quality in Public Health, 3(1), 167175.

https://doi.org/10.30994/jqph.v3i1.60

Ibrahim, A. M. (2017). Effect Of An Educational Program About Occupational Health And Safety On Knowledge, Attitude, And Practice Of Workers In Textile Factory In Damietta City. IOSR Journal of Nursing and Health Science, 6(2), 66-78. https://doi.org/10.9790/19590602016678

Indrayani, \& Sulianti, I. (2014). Kajian Penerapan Kesehatan dan Keselamatan Kerja (K3) dalam Proses Belajar Mengajar di Bengkel dan Laboratorium Politeknik Negeri Sriwijaya. Jurnal Teknik Sipil, 10(1), 27-36.

Margareta Pratiwi, \& \& Eka. (2016). Hubungan Pemakaian APD, Hygiene Perusahaan dan Riwayat Penyakit dan Penyakit Dermatitis Alergi Akibat Kerja di PT PSUT Jambi Kabupaten Muaro Jambi. Scientia Journal, 5(2), 173-179.

Mehrparvar, A., Mirmohammadi, J., Fazlalizadeh, M., Ghoveh, M., \& Omrani, M. (2012). A survey of hearing protection devices usage in industrial workers in Yazd- Iran. Occupational Medicine, 3(46), 1-6.

Notoatmodjo, S. (2012). Promosi Kesehatan dan Perilaku Kesehatan. Rineka Cipta.

Oakley, K. (2008). Occupational Health Nursing (third). John Wiley \& Sons.

Odu Ndep, A., Ebere Okeke, J., Nsa Ekpenyong, B., \& Osuchukwu, N. C. (2020). Using the Health Belief Model to Describe Factors Influencing Factory Workers' Workplace Safety Practices in Nnewi, Anambra State, Nigeria. International Journal of Innovative Science and Research Technology, 5(1), 1-5. www.ijisrt.com

Puteri, A. D., \& Afrianti, S. (2019). FaktorFaktor Yang Berhubungan Dengan Kecelakaan Kerja Pada Karyawan Unit Pelayanan Teknik di PT. PLN Bangkinang Kota. Jurnal Kesehatan Masyarakat, 3(1), 23-34.

Putra, D. Y. (2017). Faktor-Faktor Yang Berhubungan Dengan Praktik Kepatuhan Pekerja Terhadap Process Safety Information (Psi) Di Area X PT. Y. Jurnal Kesehatan Masyarakat, 5(5), 96-104.

Rachmadiyawati, M. (2020). Faktor Yang Berhubungan Dengan Perilaku Penggunaan Alat Pelindung Diri Pada Pekerja Bagian Produksi PT. Semen Bosowa Banyuwangi. Majalah Kesehatan Masyarakat Aceh, 3(1), 112118.

Suma'mur. (2014). Higiene Perusahaan dan Kesehatan Kerja. CV Sagung Seto. 